\title{
Dietary Behavior Of University Going Female Adolescents In Pakistan: Issues, Challenges And Strategies For General Health And Academic Performance
}

\author{
Rubina Fazal \\ \& \\ Anjum Bano Kazimi \\ Department of Education \\ Iqra University
}

\begin{abstract}
Young generation is the major human capital of any country, especially female adolescents as they are future mothers and future mentor. Adolescence is a critical period of the human life cycle، during this time hormonal, physical and psychosocial development occurs rapidly, any insufficient and poor dietary intake during this period impact on physical and mental health. According to World Health Organization (WHO) 51\% young females in Pakistan, suffer with malnutrition, whereas, National Nutrition Survey of Pakistan (2011) 35-39\% of adolescent female affected with nutritional deficiencies. This study attempts to explore the factors related to dietary behavior of female adolescent students and its effect on their general health and academic performance. Qualitative approach through a focus group discussion with semi-structured questionnaire was applied. 10 participants were selected purposefully. Result shows that general health of female adolescents is very deprived. Anemia, headache, low concentration, inattention inactiveness, frequent illness, majority have joint problems in early age, harsh behavior, short-temper as main issues. The major challenges were selection and availability of unhealthy food in canteens, influence of peer in food choices, skipping breakfast, commonly used fast foods or junk foods, high consumption of soft, energy drinks. Participants suggested a need of collaborate effort to overcome the immense problem
\end{abstract}

Keywords: Adolescents, Dietary Behavior, General Health, Academic Performance.

$$
\begin{aligned}
& \text { تلخيص }
\end{aligned}
$$

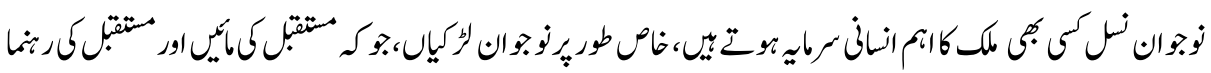

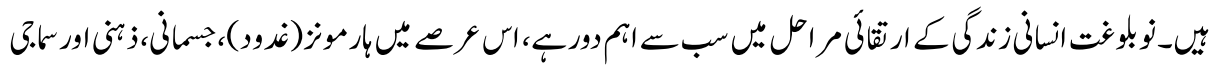

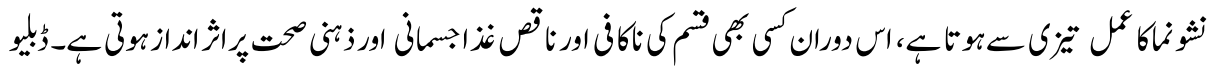

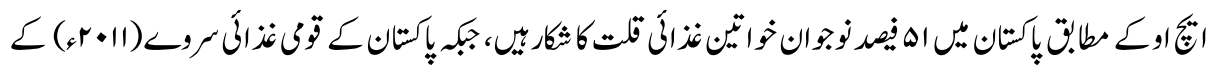

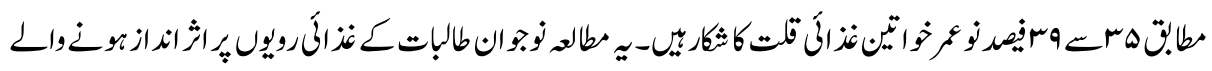




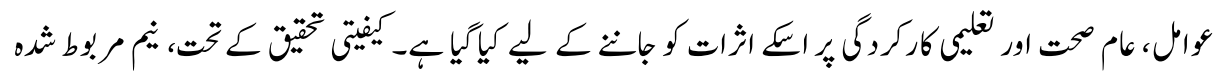

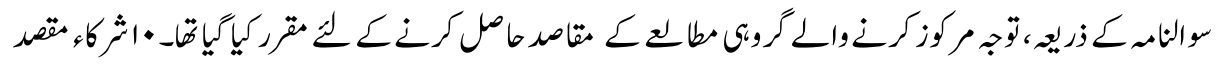

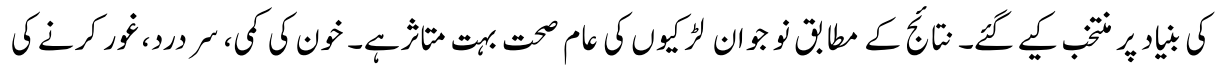

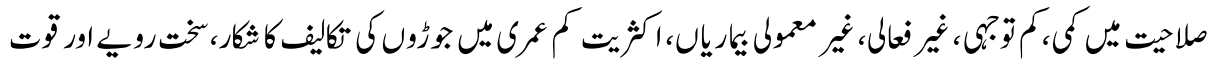

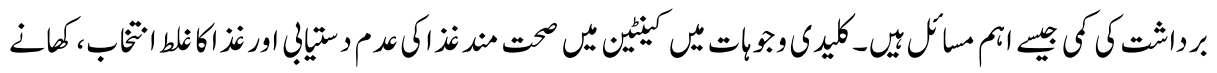

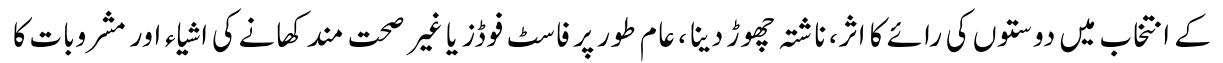

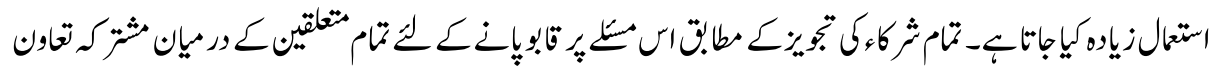

$$
\begin{aligned}
& \text { كز }
\end{aligned}
$$

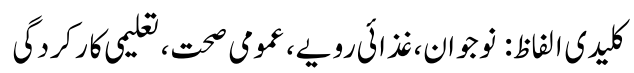

\section{Introduction}

The progress of any country depends significantly on the quality of education. It has competed for wellbeing and vital component for academic accomplishment at school and in advanced education. Thus, education is a solid indicator of long-lasting wellbeing and personal satisfaction in various people, settings, and time. Therefore, in the context of universities, advancing the well-being and health of all individuals implies encouraging effectual learning (Ghosh, 2013).

Pakistan is the sixth most heavily populated nation of the world, having about more than 160 million peoples, comprise the adolescents represent of the one-fourth of the populace, however, haven't got much consideration as for their health needs and wellbeing (Fatima, Yaqoob \& Hafeez, 2014). Enhancing the nutrients status of adolescents is very important for the future economic increase. Adolescents are our future human capital: they're future employees, future careers, future marketers, future parents and some of these roles are negatively affected by poor nutrition status (Liere et al., 2017).

Adolescence is an intermediary period amongst youth and adulthood. It is thought to be the most vital and adaptable time of life where development and improvement are joined by physical, physiological, behavioral, and social changes (Fatima et al., 2014). Adolescence is a critical period for both physical and mental growth, as the eating habits and nutritional intake of adolescents have a long-term influence on their health. All through this stage the demands for nutrients increases representing a more serious danger of nutritious insufficiencies (Fatima et al, 2014). Adolescence being a basic time of human life is subjected to an assortment of difficulties and incorporates different dietary and social insurance rehearses. University life is a crucial period with respect to 
unfortunate changes in eating practices in learners. The beginning university is frequently connected with learner having more self-sufficiency over their dietary decisions e.g., food buying and cooking (Plotnikoff et al., 2015). During this era, adolescents adopt or develop food preferences and make food choices based on associations with feelings of being accepted and having fun with peers and may use food as a way to exert independence from families and parents (Stang \& Story, 2005).

As the adolescent students become lethargic and decrease his / her physical activities (become passive) and become careless regarding his dietary habits more chances are visible in increased obesity or malnutrition. It has been proven through researches that physically active students have improved memory, attentiveness, concentration and classroom behavior. Other researchers have indicated that students who are physically active during the week time have improved social skills reveal through communication with peers, build self-esteem and improve stress management skills by strengthening students emotional social support system, helping maintain moderate weight status and other health issues. Furthermore, increase physical activities enhance attention during class time, decreases depression and improve the perception level of student (Snelling, 2015).

Nutritious status can straight forwardly influence mental limit among students. For instance, insufficient in taken iron, even in early stages, can diminish dopamine transmission, in this way contrarily affecting cognition. Insufficiencies in different vitamins and minerals, particularly thiamine, vitamin $\mathrm{E}$, vitamin $\mathrm{B}$, iodine, and zinc, are appeared to restrain intellectual capacities and mental focus. Females are at a much higher risk of deficiencies than male, particularly, nutrients such as protein, calcium and iron. Moreover, amino acids and starch supplementation can enhance recognition, intuition, thinking, and reasoning (Extension, 2014).

Healthy diet can also end result in several social benefits as well. It manage relationships, social situations and decreased mood swings, Dr. Mauro Di Pasquale, shows that the utilization of refined sugar and processed carbohydrates causes spikes in blood sugar that can result in rapid changes in mood and temperament. A healthy diet will keep students even-tempered during social situations which is necessary element for concentration during studies (Benjamin, 2015).

Adolescent girls are the subgroup of the population in which eating disorders most commonly occurs. Unhealthful dieting behaviors in which meals are skipped, energy intake is severely restricted, or foods groups are lacking are common. Dieting behaviors have been found to be associated with inadequate intakes of essential nutrients. Restricting behaviors, leading adolescents to experience hunger or cravings for specific foods may place them at risk for different eating disorder like binge-eating (Brown et al, 2011). According to Demographic Survey (2013) and National Nutrition Survey of 
Pakistan, 2011 (Bhuttaet al., 2011), the nutritional status of Pakistani girls in late adolescence (aged 15-19 years) is distressing, with weak development during childhood $(22 \%)$, and very high prevalence of micronutrient deficit, such as $54 \%$ female adolescents suffer in anemia, 49\% have deficiency of folic acid, $42 \%$ deficit in zinc and $40 \%$ lack in vitamin A (Liere et al., 2017).

A Food Consumption Survey, 2014-15 (Liere et al., 2017) within the regions of Sindh and Punjab suggests that the regular diet of an adolescent girl is of bad nutritional quantity and quality (especially low in iron), that could cause micronutrient insufficiency. Health and learning are interlinked. An appropriate adjustment of nutrients in this developmental period is basic for normal health. Deficiencies of nutrients like iodine and iron can deteriorate cognitive and motor development and these impacts are mostly irremediable. When students are healthy; physically and emotionally, with good nutrition, safety and a sense of personal belonging, they are more likely to attend college / university and be ready to learn, perform better in ranges of interest, conduct and behavior, participation, regularity and complete their assignments more efficiently than learners who don't eat well (Urban Child, 2011). Research showed the powerful connection between poor health and academic failure, and it shows that health issues and inadequate school environments affect students' attendance, grades and ability to learn (University of California, 2011).

Each learner can possibly do well. Neglecting to give great nourishment puts them at hazard for passing up a major opportunity for meeting that potential. However, the quality of students' diet impacts their performance in the educational institute. Be that as it may, making a move today to give more advantageous decisions in universities can set learners up for an effective future loaded with potential outcomes. Subsequently, to enhance intellectual and cognitive capacity, learning and academic accomplishment in adolescence needs to get consideration by researchers and policymakers.

Hence, the focus group discussion set up to identify the issues and challenges of dietary behavior of female adolescent's students and how its effect on their general health and their academic performance. Furthermore, to accumulate opinion and suggestion in order to facilitate the development of effective programs intend to improve healthy eating behaviors in university students.

\section{Review of Related Literature}

In 1948, the constitution of the World Health Organization (WHO) defines human health in a very wider way which has not been revised since. "It is a state of complete physical, mental, and social well-being and not merely the absence of disease or infirmity" (World Health, 2006). Healthiness of individual is a grouping of physical, mental/emotional, and 
social/spiritual fitness. These three elements of health are linked together, to acquire absolute wellbeing it is important that all three elements ought to be balanced (Mercer, n. d.).

Physical Health deals with the body's capability to function. It means perfect functioning of the body (Aivalli, 2015). Physical health is described by way of someone's sleep and eating habits, in addition to the quantity of exercise they get and their oral hygiene (Mercer, n.d.). Physical fitness has numerous components: do exercises on a regular basis, consumption of nutritious food and drinks, getting enough sleep and have a feeling of relaxation, to avoid alcohol and smoking, preserve a beneficial weight and committing high-quality hygiene (Tarrkent, 2017).

Mental Health incorporates human emotional, mental and cognitive power. It has an effect on how we think, assume, sense, replicate, and make a movement. It additionally enables us to determine how we contend with stress and anxiety, relate to others, and generate alternatives (U.S. Department of Health \& Human Services, 2017).Mental fitness is recognized and assessed through our capability to deal with the anxiety or pressure of everyday existence and keep a usually thrilled and high-quality approach regarding life. It also includes the learning capabilities of a person (Mercer, n.d.).

Social Health involves person ability to form pleasing positive as well as supportive interpersonal relationships with friends and then others. It also pertains to personal capacity to modify without difficulty, to extremely good social conditions and take movement effectively between various situations. Spouse, colleagues, neighbors, and friends can all preserve healthful relationships together with one another. Everything regarding those relationships consists of extreme conversation talents, sympathy for others and a sense of responsibility (Koshuta, 2015).

The health of individuals and communities depend on many factors. WHO and Zimmerman \& Snow (2012) determine the three main factors affecting health; social and economic environment, physical environment and person's individual characteristics and behaviors. These factors include genetics, the environment, life cycle, and lifestyle, each one has a reasonable impact on health and many a time they interact with each other to create a fruitful result. For example, the choice of food is dependent on the income of the family. This fact conditions the quantity and quality of food to be purchased, which in returns affects the nutrition of family.

Dietary Behavior: To be healthy some nutrients are required throughout life in the diet, but the number of nutrients needed may vary keeping in view the age, growth and development stage. Nutrients required in every stage of the life cycle can be met through a variety of foods and food practices. No one can suggest a single diet for every individual. Diverse cultures and religions recommended diets which give foundations for 
fulfilling the nutritional needs of the individuals and sometimes make necessary modification in the diet when required. People of a specific culture or religion may have similar dietary practices as they share common taboos related to food and its intake practices (Brown, et al., 2011). Personal behavior, family status, social and physical environments have a definite effect on dietary behavior. Deliend, et al., (2014) specified multiple aspects that can affect the dietary behavior of university going students. Individual, Social, Physical, macro and university environment are the key factors that affect the dietary behavior of an individual. Along with these major influences, Zimmerman \& Snow (2012) point out a number of other factors affects the dietary choices individuals make, including; early food experience, taste, texture and appearance, habits and emotions, economic, culture, geography, social factor like peer pressure, advertizing and health concerns.

\section{Effect of Dietary Behavior on Physical, Mental and Social Health}

Well, balanced life is the result of having balanced diet, which means selecting food from every food groups in the amount recommended for specific age and avoiding such items like sugar, salt, fats and alcohol which could be a hazard to health. A person's all-around development is based on healthy eating (Allane, 2017). An individual physical health, energy, stamina, tempo, rapidity, and level of performance are all powered by means of the meals humans consume. What a person consumes decides how they deal with everyday physical activities like exercise, housekeeping, educational activities, homework, job, shopping for a family. Consuming a wholesome diet allows body actions to be finished comfortably. An unhealthy diet with bad food choices could make each movement a prime effort full of tension, anxiety and pain (Tomm, n.d.).

The association between cognitive and mental health and nutrition is significant. Human perception, thoughts, and learning are elements of cognitive development. An appropriately balanced diet is crucial for normal brain growth. Lack of nutrients like iron and iodine can weaken mental and motor development, and these effects are often irretrievable if prolonged for a long period (Nutrition and Early, 2011).

Allane (2017) and Extension (2014) cited several studies which showed that dietary status can have a direct effect on cognitive ability amongst students. A lack of necessary vitamins mainly vitamin $\mathrm{A}$, vitamin $\mathrm{B}$, vitamin $\mathrm{B} 12$, vitamin $\mathrm{E}$, and minerals, including, iron, calcium, zinc, and iodine isn't always simplest correlated with signs and symptoms of despair but additionally proven to inhibit mental abilities, alertness and concentration. Further studies (as cited in Moser, 2012) show that nutrition has an effect on intellectual development in particular for younger human beings. Oddy et al. found that deprived mental fitness consequences in middle stage of teenagers have been associated with an eating excessive red and processed meats, dine-out, refined and sugary foodstuff. 
Whereas, those take higher consumption of fruit and leafy vegetables showed enhanced mental fitness results. Excessive use of sugar alone can negatively impact young individual's mental fitness. In Oslo, Norway, researchers determined a strong affiliation between using of sugared soft drink and cognitive and mental health troubles. Another study proved an optimistic association among intake of sugary soft drinks and chocolate, candy or sweet products and dangers for suicidal actions among youngsters aged between 12 to 19 years in Jiangsu Province, China.

Good eating practices play a vital role in a person's social health. Professionals were promoting the physiological benefits of a healthy diet; though, a healthy eating routine also can bring about several social advantages too. A balanced diet provides various constructive changes in individual capability to manipulate relationships and social conditions and also reduce mood swings. Nutritionists point out that spikes in blood sugar are caused by the excessive usage of processed carbohydrates and refined sugar which can bring about speedy changes in temper and temperament. A healthy food will maintain temper during social conditions that are a necessary component for attentiveness during learning (Benjamin, 2015).

\section{Dietary Behavior and Academic Performance}

It is necessary to have appropriate social, mental and physical fitness for students to completely participate in educational activities and also concentrate on learning. Learning and health are interrelated. If students are well; physically and emotionally, with proper nutrients, protection and a sense of personal belonging, they're much more likely to be present at school and be geared up to learn. Unhealthy dietary behavior may cause different nutrients deficiencies; Malnutrition has a vital effect on the central nervous system. Protein-energy malnutrition additionally impacts a person's learning capabilities, student's mental power, intellectual and cognition, intelligence, overall performance, and behavior (Padron, 2007). Dani et al., (2005) indicated that essential fatty acid deficiency produces symptoms of attention deficient/hyperactivity disorder (ADHD).These signs and symptom such as mood tantrums, sleep problems, learning and health issues. Deficiency of vitamins (i.e., vitamins A, B6, B12, C, and D) are related to lower grades and higher rates of absenteeism and tardiness amongst students (National Center for Chronic Disease, 2014).Iron insufficiency throughout infancy may cause everlasting harm to the child's brain Iron and iodine deficiency seriously influences youngsters' gaining education, it influences the brain enzymes concerned in cognition and conduct. Excessive deficiency leads to seriously poorer performance on exams of learning and behavior (National Food Service). 


\section{Methodology}

To achieve the aim of the study, a qualitative approach, focus group discussion was conducted by semi-structured questionnaire to explore the subjective opinion of mothers, teachers, and nutritionists concerning the dietary behavior, health problems and academics issues of universities students under the age group of later adolescents. As well as to find out the perceptions about importance of health in university students to achieve high-quality academic performance, discussed the common health issues of students, detect the relation of dietary behavior on overall health wellbeing (physical, mental and social health) and academic performance, identify the barriers and enablers of healthy behavior and offer suggestions to develop a strategy to promote healthy eating behaviors in students to improve academic performance.

\section{Target Population}

To get information, opinion and suggestions during focus group discussion, this study targets the population of university teachers; mothers have university going young female and nutritionists served in the hospital as a dietician and consultant, to attain relevant data.

\section{Sampling Technique and Sample Size}

Through purposive sampling technique, total 10 participants; four university teachers, four mothers and two nutritionists were selected.

\section{Analysis of Focus Group Discussion}

Focus group discussion was audio recorded, and the moderator also takes supplementary notes throughout the session. After recording the interview, the audio recordings were transcribed and data attained from the focus group discussion were analyzed, grouping the rising codes, create the theme and build up the structural synthesis.

\section{Results and Discussion}

After the analysis of focus group discussion, multiple themes emerged on problems, challenges, and strategies for improving general health and academic performance of female adolescents

i. Description of Healthy Person: According to the participants a healthy person is those who give better performance in all areas of development like physical, social, mental or emotional development. One participant clarified that: We say to someone a healthy person when they normally grow in all four areas of 
development. Another participant further added that a physically active person may be having a lean structure, did their entire work without any hindrance or complains of fatigue and illness, consider as a healthy person. In our society, we think that they are weak, do not eat properly but if they are less ill, physically active, they are healthy. Some children look healthy but in a week or month, they are suffering or ill, have a cold and sour throat. It means they are not healthy. One more participant further explained that: We can say that healthy people are those who properly perform their activities and have no complaints of illness on regular basis.

ii. General Health Status of Adolescents: All participants thought that the general health status of adolescents is very deprived. They mention that: students have physical compliance and physical problems. Mentally they are weak, have learning problems. Socially their behavior is so harsh. Their behavior going towards extremism, thus we will categorize today's adolescents' health as very poor. Same evidence from Demographic Health Survey (DHS) 2013 indicated that in Pakistan, youth go through bad nutrients, high level of stunting (22\%) and obese (16\%) among adolescent women elderly 15-19 years. National Nutrition Survey (NNS) 2011 and Food Consumption Survey, 2014-15 indicate the distressing deficiency levels of micronutrient. Within the areas of Sindh and Punjab normal diet of adolescent girls is of poor quantity and quality, that could result in micronutrient deficiencies, with more than half of i.e. 54\% of adolescent females 15-19 years stricken by anemia; $21 \%$ are iron deficit; $49 \%$ are folic acid deficient; $42 \%$ are zinc deficient; and $40 \%$ are vitamin deficient.

iii. Factors influence Healthy Dietary Behavior: Participants point out some of the major factors which influence healthy dietary behavior in adolescents, these are:

- Skipping Breakfast: It is one of the major factor revealed by the participants. Girls do not have breakfast now a day and regularly two to three girls become unconscious at universities because of not having breakfast. This discussion has similarity with the previous result of the studies (Arshad \& Ahmed, 2014;Allane, 2017), indicated that that majority of the students omitted their breakfast and it was clearly associated with their academic performance i.e. those who skip breakfast feel tired, sleepiness or develop a headache and remain inactive during the study and can't concentrate on their studies.

- Inattention of Mothers: According to the participant inattention of a mother is one of the major causes of skipping breakfast. Majority of the house wife's mother get up late in the morning and the child went institute without having breakfast. If mother build habit of essentially taking breakfast in early childhood, or they give proper awareness of healthy food choices to the children so they become habitual in younger age and always consumed meals on time and select only those food products which are healthy or if healthy foods are not available in canteen, they 
carry lunch from home. A teacher argued that: when the student health is deteriorated and the teacher asked why not to have breakfast, they say that my mother was sleeping, so did not come to serve breakfast.

- Junk Food or Fast Foods: Due to the ignorance of breakfast, students feel hungry between 10 am to $11 \mathrm{am}$. At that time they eat whatever available in university canteen, and then it becomes a habit to take junk food or fast food. One of the teachers replied that: when we question about why they skip breakfast they said that we have no habit of eating breakfast or complain that we get vomit.

- Peer Pressure: One of the teachers specified that one main reason behind consumed junk food or fast food was peer influence or pressure. They mostly choose those food items which prefer their friends. At this stage of life, they like to spend more time with their friends' than their family members. Also, they are immensely status conscious and like to eat food from renowned restaurants or outlets to show the status symbol on others. When the food served in the hotel, initially they take a picture of food and share it on Facebook or on the other day gladly tell in the university that we eat this or that yesterday.

- Inactivity: Nowadays, one of the major factors is inactivity. Students don't take part in physical activities at the university. Also most of the time they spend in a home with their mobiles or computer, which affects their digestion and metabolic system. Because of which they do not feel hungry, and eat junk food snacks instead of eating a regular meal. The results of previous study (Chan et al., 2016) also showed that the developing occurrence of taking snacks among teens leads to the hazard of weight problems, especially among physically inactive individual or snacking at the time of watching television.

- Dieting: According to the nutritionist, the young generation, especially females are figure conscious, which gives them simple dieting to severe eating disorders. As a result of dieting, they become thin or underweight and usually neglect essential nutrients in their regular diet. This is the risk of being anemic and other necessary nutrients deficiencies. The previous study (Mahan \& Stump, 2007) confirms that body image concerns are general in the period of adolescence. Many teens show themselves as being obese although being of regular weight, signifying a trouble of their body image. Poor body image can direct to weight control problems and weight-reduction plan.

- Availability of Healthy Food: All the participants indicated that in universities there was no accessibility to healthy food in the canteen. There is no check and balance; the student has to take the thing that is present in the canteen. Majority of the canteen in institutes have junk food or energy drinks, so the healthy choices are limited for the students. One of the participants said that: Girls do not have breakfast in the morning. 10 to 11 o'clock when they feel hungry, they take whatever they get, whether they are unhealthier like samosas, rolls etc. 
- Media: Media has a great influence on a younger generation. They watch a television that energy drinks are very powerful and give rapid energy or to eat burger or pizza gives pleasure in life etc. Due to media they become more status conscious and prefer to buy and consume those food products which are popular or trendy, without knowing its hazards.

iv. Effect of Unhealthy Dietary Behavior on Health and Academic Performance: In the discussion on the effect of unhealthy diet and academic performance, participants specified that there is a double burden, at one side we seem the obesity but on the other side there are too many cases of underweight and anemia, both are severe problems. As most adolescents are not taken iron-rich food in their diet that causes severe anemia because every month they lose blood during menses. Dani et al. (2005) cited that Iron deficiency rigorously influences on individual's learning; it affects the brain enzymes concerned in cognition and behavior. Severe iron deficiency leads to significantly poorer performance on tests of learning and behavior.

As well as if they are obese they easily get fatigue at a short time and had a great possibility to have obesity, high cholesterol, and hypertension in younger age. As results of the poor dietary habit, generally students are very weak, and they have low concentration level. Their diet is not balanced; low in iron, calcium, minerals, and vitamins, usually they get sick soon, and due to this their academic performance is affected. One of the participants further added that the condition of the adolescents to be seen is not right at all, their physical conditions, mental health, social and emotional health are affected, tolerance is very low and the stress level goes high. Moreover, another teacher pointed out that, fast food or junk foods produced oxidative stress. Its effects on brain signals, due to a weak signal, a person be ill with learning disabilities and other cognitive problems like dementia, schizophrenia etc.

Department of Health and Human Services illustrated that omitting breakfast diminish cognitive performance e.g., attentiveness, concentration, memory, processing of complex visual display and problem solving among students other than students who consumed breakfast have enhanced academic, behavioral and emotional functioning, (National Center for Chronic Disease, 2014).Further research pointed out that students indulged in a diet high in junk food were more likely to be hyperactive; a lack of focus and an inability to concentrate on work, relationships and lifestyle than those who did not (Ireland, 2017). Stea and Trostveit (2014) also concluded that students with a regular meal pattern with an intake of healthy food items and being physically active had high academic achievements.

v. Role of Stakeholders to improve Healthy Dietary Behavior: According to the participants that, you must work together for improving the |health condition of adolescents' female students. They are our future; we must take a step. 
Participants suggested that mother is the most important person who takes the first step. From the early childhood mother give awareness about healthy diet and healthy choices, must provide lunch from home, and develop breakfast habit. Other than mothers, teachers are the role model of students, if the teacher eats junk food in their lunch, in front of students, so it's not right. That's why the first teacher will have to change. Thus, switch between healthy choices than junk or fast food. Use fresh juices than soft drinks or salad, fruits instead of samosas. Fries, chat etc. Furthermore, from the early class, there must be chapters in the book related to nutrition and diet. Also at university level arrange awareness lectures, seminars after fifteen days or monthly basis. Increase co-curricular activities make proper policy about canteen; each and every institute must have to check the canteen in terms of availability of healthy foods and sanitation condition. As well as media is also more powerful tool; frequently use print and electronic media for providing awareness about healthy food.

\section{Conclusions and Recommendations}

This study helps to reveal dietary practices of female adolescents' students, commonly use in the university level. It also identifies the health-related issues faced by teachers and students in terms of regularity, concentration, classroom performance, communication, academic achievements etc. Major finding illustrated that the general health status of adolescent females is very poor. Dietary behavior that is seen more frequently among adolescents include skipping meals, especially breakfast, or irregular consumption of meals, excessive snacking and junk or fast foods, eating away from home, especially fast food venues or take-away fast food meals, high consumption of soft drinks distinctive likes and dislikes for foods and excessive dieting. Similar results were also found in the previous studies conducted by Mann \& Truswell, (2002), Mahan \& Stump, (2007), Brown et al., (2011), Arshad \& Ahmed (2014) and Allane, (2017).

The role of mother and teachers are very important in providing awareness and selection of healthy food choices, as they are role models. As well as media play a crucial part in providing knowledge about healthy diet and healthy choices, banned on energy drinks advertisements as it portrait fantasy. There should be check and balance in canteen products. Fresh juices are the alternative option instead of soft or energy drinks. There should be seminars or lectures in universities on monthly basis to provide awareness about good nutrition and it's important. Furthermore, there should be different health programs for the target group at the government level.

Hence, this study contributed to the field of education especially in the effective learning process, not only in the higher education level but also significant for all levels of education. It helps to provide the guideline for the stakeholders (Planners, teachers, 
learners etc.) to develop strategy and strengthen implementation program to encourage healthy dietary behavior and improve overall health which raises the quality of education, recover academic performance and remove the barrier of effective teaching and learning environment.

\section{References}

Aivalli, P. K. (2015, January 7). Concept of Health. Article posted to https:// www.slideshare.net/PraveenAivalli/concept-of-health-43306076

Allane, F. (2017, October 3). How does healthy eating affect physical, mental \& social health? Article posted to https://www.livestrong.com/article/445701

Arshad, N. \& Ahmed, U. (2014). Impact of Breakfast Habits on Education Performance of University Students. International Journal of Academic Research in Progressive Education and Development, vol.3:1, pp.255-270.

Benjamin, D. (2015, August 8). Social Benefits of a Healthy Diet. Article posted to https://www.livestrong.com

Bhutta, Z., Soofi, S., Zaidi, S., Habib, A. \& Hussain, M. (2011). Pakistan National Nutrition Survey, 2011. Available at: https://ecommons.aku.edu/pakistan_fhs_mc _women_childhealth_paediatr/262

Brown, J. E. et al. (2011). Nutrition through the lifecycle (4th ed.). USA: Wadsworth Cengage Learning.

Chan, k., Tse, T., Tam, D. \& Huang, A. (2016). Perception of Healthy and Unhealthy Food among Chinese. Young Consumers, vol.17:1, pp.33-45. Retrieved from https://doi.org/10.1108/YC-03-2015-00520

Dani, J., Burrill, C. \& Adams, B. D. (2005). The Remarkable Role of Nutrition in Learning and Behaviour. Nutrition \& Food Science, vol.35:4, pp.258-263. Retrieved from https://doi.org/10.1108/00346650510605658

Deliend, T., Clarys, P., Bourdeaudhuij, I., D. \& Deforche, B. (2014). Determinants of Eating Behaviour in University Students: A Qualitative Study Using Focus Group Discussions. BMC Public Health, vol.14:53, pp.1-12. doi:10.1186/1471-2458-1453 Retrieved from http://www.biomedcentral.com/1471-2458/14/53 
Extension. (2014). 3 Ways Nutrition Influences Student Learning Potential and School Performance. Available from http://articles.extention.org

Fatima, F., Yaqoob, A. \& Hafeez, A. (2014). Nutritional Assessment of adolecent Girls Living in Cherah Union Council. Journal of Pakistan Medical Association, pp.64:11, pp.1220-1224.

Ghosh, S. (2013). The Role of Adequate Nutrition on Academic Performance of College Students in North Tripura. International Journal of Health Science and Research, vol.8:8, pp.56-63.

Ireland, K. (2017, October 3). How does junk food affect the way you concentrate? Article posted to https://www.livestrong.com/article/509860-why-is-candy-badfor-your-health

Koshuta. J. (2015). What is social health? Definition \& examples. Retrieved from http:// study.com/academy/lesson/what-is-social-health-definition-examples.html

Liere, M. V., Bhutta, Z. A., Blomberg, J. H. \& Mahmood, S. (2017). Embodying the Future: How to improve the nutrition status of adolescent girls in Pakistan? Global Alliance for Improved Nutrition, 1-48. Retrieved from www.gainhealth.org

Mahan, L. K. \& Stump, S. E. (2007). Kause's Food \& Nutrition Theraphy (12th ed.). Philadelphia, USA: Elsevier Health Sciences.

Mann, J. \& Truswell, A. S. (Eds.). (2002). Essentials of Human Nutrition (2nd ed.). New York, USA: Oxford University Press.

Mercer, L. (n.d.). The Health Triangle: Mental, Social \& Physical Definitions. Retrieved from: https://healthyliving.azcentral.com/the-health-triangle-mental-socialphysical-definitons-12180709.html

Moser, C. (2012). How diet and nutrition affect mental health? Focal Point, vol.26:1, pp.15-17. Retrieved from https://www.pathwaysrtc.pdx.edu/pdf/fpS1205.pdf

National Center for Chronic Disease Prevention and Health Promotion. (2014). Health and Academic Achievement. Retrieved from https://www.cdc.gov/healthyyouth/ health_and_academics/pdf/health-academic-achievement.pdf 
National Food Service Management Institute. . Meal Time Memo for Child Care Nutrition and Cognitive Development. Retrieved from http://www.nfsmi.org/ documentlibraryfiles/PDF/20080612091850.pdf

National Institute of Population Studies (NIPS) [Pakistan] and ICF International. (2013). Pakistan Demographic and Health Survey 2012-13. Islamabad, Pakistan, and Calverton, Maryland, USA: NIPS and ICF International. Retrieved from http://dhsprogram.com/pubs/pdf/FR290/FR290.pdf

Nutrition and Early Brain Development (2011, March 25). Article posted to http://www.urbanchildinstitute.org/articles/updates/nutrition-and-early-braindevelopment

Padron, R. N. (2007). The Effects of Protein Energy Malnutrition on the Central Nervous System in Children. Rev Neurol, vol.2:44, pp.71-74. Retrieved from https:// www.ncbi.nlm.nih.gov/pubmed/17347950

Plotnikoff, R. C., Costigan, S. A., Williams, R. L., Hutchesson, M. J., Kennedy, S. G., Robards, S. L., et al. (2015). Effectiveness of Interventions Targeting Physical Activity, Nutrition and Healthy Weight for University and College Students: A Systematic Review and Met Analysis. International Journal of Behavioral Nutrition and Physical Activity, vol.45:12, pp.1-10.

Snelling, A., Belson, S. I., Beard, J. \& Young, K. (2015). Associations between Grades and Physical Activity and Food Choices. Health Education, vol.115:2, pp.141151. Retrieved from http://dx.doi.org/10.1108/HE-03-2014-0028

Stang, J. \& Story, M. (Eds.). (2005). Guidelines for Adolescent Nutrition Services. Retrieved from http://www.epi.umn.edu/let/pubs/adol_book.shtm

Stea, T. H. \& Torstveit, M. K. (2014). Association of Lifestyle Habits and Academic Achievement in Norwegian Adolescents: A Cross - Sectional Study. BMC Public Health, 14(829), 1 - 8. Retrieved from http://www.biomedcentral.com

Tarrkent, L. (2017, October 3). Health Triangle Facts. Article posted to https:// www.livestrong.com/article/42697-health-triangle

Tomm, S. (n.d). How does eating healthy affect your physical, mental \& social health? Article posted to http://healthyeating.sfgate.com/eating-healthy-affect-physicalmental-social-health-6972.html 
University of California Sanfrancisco. (2011). Student Health and Well Being: Are vital to academic result. Retrieved from http://www.attendanceworks.org/wp-content/ uploads/2017/09/Student_Health_Brief_23March20111.pdf

Urban Child Institute. (2011). Nutrition and Early Brain Development. Retrieved from http://www.urbanchildinstitute.org/articles

U.S. Department of Health \& Human Services. (2017, August 29) .What is mental health? Retrieved from https://www.mentalhealth.gov/basics/what-is-mentalhealth

World Health Organization.(2006). Constitution of the World Health Organization Basic documents. Retrieved from http: //www.who.int/governance/eb/ who_constitution_enpdf

Zimmerman, M. \& Snow, B. (2012). An Introduction to Nutrition (Vol. 1.0). Retrieved from https://books.google.com.pk/books

Rubina Fazal is PhD Scholar in the Department of Education, IQRA University, Karachi.

Dr. Anjum Bano Kazimi is Professor in the Department of Education, IQRA University, Karachi. 